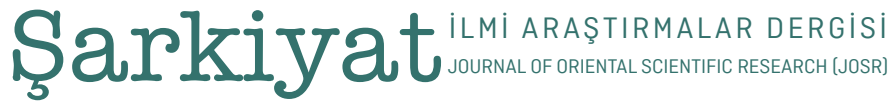

Cilt/Volume: 13, Sayı/Issue: 1 (Nisan/April 2021) Sayfa/Page: 6-25

\section{EDIRNE VILAYET SALNÂMELERINE GÖRE XIX. YÜZYILIN SONUNDA ÇORLU KAZASINDA SOSYAL VE EKONOMIK HAYAT}

\author{
Pinar Doğanay \\ Gazi Üniversitesi Sosyal Bilimler Enstitüsü Yakınçağ Anabilim Dalı \\ snpnrdoganay@gmail.com, ORCID ID: https://orcid.org/0000-0001-9733-2172 \\ Article Types / Makale Türü \\ Research Article / Araştırma Makalesi \\ Received / Makale Geliş Tarihi \\ 25/01/2021 \\ Accepted / Kabul Tarihi \\ $30 / 03 / 2021$
}

Doi: https://doi.org/10.26791/sarkiat.868111 


\section{EDIRNE VILAYET SALNÂMELERINE GÖRE XIX. YÜZYILIN SONUNDA ÇORLU KAZASINDA SOSYAL VE EKONOMIK HAYAT}

\section{ÖZ}

Osmanlı arşiv belgeleri içerisinde yer alan ve şehir tarihi araştırmalarının önemli kaynaklarından olan salnâmeler, mevcut yerleşim yerinin tarih, coğrafya, eğitim, kültür, ekonomi, sosyal ve idari yapısı hakkında detaylı bilgiler içerirler. Bu bağlamdan yola çıkarak XIX. yüzyılın sonlarında Tekfurdağı Sancağı'na bağlı kaza statüsünde bulunan Çorlu'nun mevcut sosyal ve ekonomik yapısının ortaya konulmasının amaçlandiğı bu çalışmada, Edirne Vilayet Salnâmeleri temel kaynak olarak kullanılmıştır. Yapılan çalışmada, Çorlu kazasının, Müslümanların ve Gayrimüslimlerin birlikte yaşadığı bir yerleşim yeri olduğu tespit edilmiştir. Çorlu kazası, İstanbul'un tahıl ve et ihtiyacının karşılandığı yerleşim yerleri arasında yer almıştır. Halkın büyük bir kısmının geçimini tarım ve hayvancılıkla sağladığ1 kazada özellikle küçükbaş hayvan yetiştiriciliğinin yaygın olarak yapıldığ edilmiştir. Buğday, arpa, yulaf, üzüm, kavun, karpuz, vb. ürünler, kazanın tarımsal üretiminde önemli yer tutmuştur. $\mathrm{Bu}$ ürünler arasında yer alan buğday ekseriyetle saray mutfağında tercih edilmiştir. Sanayi alanında ise güçlü bir gelişimin görülmediği kazada, küçük çaplı bazı sanayi kuruluşları mevcuttur.

Anahtar Kelimeler: Vilayet Salnâmeleri, Edirne, Tekfurdağı, Çorlu, Sosyo-Ekonomik Yap1.

\section{SOCIAL AND ECONOMIC LIFE IN CORLU DISTRICT AT THE END THE OF THE XIX. CENTURY ACCORDING TO EDIRNE PROVINCIAL SALNAMES}

\section{ABSTRACT}

Salnames, which are one of the important sources of the Ottoman history city, contain detailed information about the history, geography, education, culture, economy, social and administrative structure of settlements. Based on this context Edirne Province Salnames were used as primary sources in this study aiming to reveal the current social and economic structure of Çorlu, which was county of the Tekfurdağ ${ }_{1}$ Sanjak at the end of the XIX. century. It has been determined that Muslims and non-Muslims lived together in Çorlu county. Çorlu district was one of the settlements in Istanbul where grain and meat needs were met. In this county, where most of the people earn their living from agriculture and animal husbandry particularly, sheep breeding was carried widely. Wheat, barley, oats, grapes, melons, watermelons, etc. products have an important place in the agricultural production of the district. Wheat, which is among these products, was mostly preferred in the palace cuisine. In this district, there was no strong development in the industrial area. There were small-scale industrial establishments in the district. However, these did not have power to seriously affect the current economic structure.

Keywords: Provincial Salnames, Edirne, Tekfurdağı, Çorlu, Socio-Economic Structure. 


\section{GíRiş}

С arsça “yı1, sene” demek olan "sâl” kelimesi ile «mektup, kitap” anlamında kullanılan "nâme” kelime-

lerinden türetilmiş olan salnâme, yıllık anlamına gelmektedir. ${ }^{1}$ Illk defa Tanzimat’tan sonra Mustafa Reşit Paşa döneminde yayınlanmaya başlanan salnâmeler, tarih, coğrafya, eğitim, kültür, ekonomi, sosyal ve idari yapı gibi pek çok konu hakkında detaylı bilgiler içerirler. Kendi içerisinde birden fazla kategoriye ayrılan salnâmelerin en eski ve en uzun ömürlüsü Devlet Salnâmeleridir. Padişah Abdülmecid'in saltanatı sırasında Sadrazam Reşit Paşa'nın isteği ile Ahmet Vefîk Paşa tarafından hazırlanarak, 1847 yılında yayınlanan ve Batı'da büyük ilgi uyandıran bu salnâme, Bianchi tarafından aynı yıl içerisinde Fransızca 'ya tercüme edilmiştir. ${ }^{2}$ Birinci Dünya savaşı yılları hariç 1918 yılına kadar düzenli olarak yayınlanan Devlet Salnâmeleri, Cumhuriyetin ilk yıllarında yayımlanmaya devam etmiştir. Devlet Salnâmeleri, yıl içerisinde meydana gelen önemli olayların yanı sıra devletin kurumsal ve idari yapısı hakkında da detaylı bilgiler içerirler. ${ }^{3}$

Salnâmelerin ikinci gurubunu ise bu çalışmanın da temel dayanağını oluşturan Vilayet Salnâmeleri oluşturmaktadır. 1866 yılında yayınlanmaya başlayan Vilayet Salnâmeleri, mevcut yerleşim yerinin idari ve demografik yapısı, mahalli tarih ve coğrafyası, tarihi eserleri, memur listeleri, üretim ve ekonomik faaliyetleri gibi pek çok konuda önemli bilgiler ihtiva ederler. ${ }^{4} \mathrm{Bu}$ nedenle, Osmanlı tarihi çalışmaları için de önemli bir kaynak olan salnâmeler, bilhassa XIX. yüzyılın ikinci yarısından itibaren Osmanlı şehirlerinin iktisadî ve içtimaî yapısının sergilemesi açısından büyük önem arz etmektedir. Salnâmelerin üçüncü grubunu ise başta Nezaretler olmak üzere çeşitli kurumların yayınladığı yıllıklar oluşturmaktadır. Salnâme-i Asker-î, Maarif Nezareti Salnâmesi, Salnâme-i Nezaret-i Umur-î Hariciye ve İlmiye Salnâmesi şeklinde sınıflandırılan salnâmeler, bu sınıfa dâhil edilmektedir. Salnâmelerin son grubunu ise resmi olmayan salnâmeler oluşturmaktadır. Bunlar daha ziyade resmi olmayan kurumlar ile özel şahıslara ait salnâmelerdir. ${ }^{5}$

Bu araştırmada, günümüzde Tekirdağ'ın en büyük ve en gelişmiş ilçesi olan ${ }^{6}$ XIX. yüzyılın sonlarında Tekfurdağı Sancağı'na bağlı kaza statüsünde bulunan Çorlu'nun sosyal ve ekonomik hayatı irdelenmeye çalışılmıştır. Tefurdağı özelinde bugüne kadar yapılan pek çok çalışma bulunmaktadır. Ancak Çorlu özelinde yapılan çalışmalar oldukça sınırlıdır. Oysa Çorlu kazası, sahip olduğu stratejik konumu nedeniyle erken dönemlerden itibaren Osmanlı Devleti'nin iaşe politikası içerisinde önemli bir yere sahip olmuştur. Bu sebeple, Çorlu kazasının Tekfurdağı Sancağı'ndan bağımsız olarak da incelenmesi gerekmektedir. Bugüne kadar Çorlu ile ilgili olarak nüfus ve temettuat defterlerini konu alan araştırmalar olmasına karşın salnâmeler üzerinden doğrudan yapılan bir araştırma bulunmamaktadır. Bu nedenle bu araştırma; Çorlu kazası ile ilgili olarak bu eksikliği doldurmayı hedeflemektedir.

Yapılan araştırmada ilk olarak, “1891-1902” yıllarına ait 12 adet Edirne Vilayet Salnâmesi incelenmiş ve gerekli kısımlar tasnif edilmiştir. Çalışmada, Vilayet Salnâmeleri'nin yanı sıra Doç. Dr. Dündar Alikılıç’ın Editörlügünde hazırlanan, "Osmanlı Döneminde Çorlu Nüfus Defterlerinde”, Ayşe Alev Direr Akhan Editörlüğünde hazırlanan, "Osmanlı Döneminde Çorlu Temettuat Defterlerinde C. I-II” ve Süreyya Atilla Sağlamçubukcu Editörlüğünde hazırlanan, “Osmanlı Belgelerinde Çorlu” ile Muhittin Tuna’nın 1963 basım tarihli, “Geçmişten Günümüze Çorlu” kitaplarından da yararlanılmıştır. Ayrıca çalışmada, Tekfurdağı özelinde yapılan çalışmalardan da istifade edilmiştir.

1 - M. Zeki Pakalın, Osmanlı Tarih Deyimleri ve Terimler Sözlüğ̈̈, C. III, (Ankara: MEB Yayınları, 1993), 105.

2 - Bilgin Aydın, "Salname”, C. 36, DİA, (İstanbul: Türkiye Diyanet Vakfı Yayınları, 2009), 51-54.

3 - M. Zeydin Yıldız -Orhan Deniz, "Maarif Salnamelerine Göre 19. Yüzyılın Sonunda Van'da Eğitim ve Kültürel Hayat”, Doğu Coğrafya Dergisi 36 (2016), 199.

4 - Tunay Karakök, “H. 1288 (M. 1871) Tarihli Kastamonu Vilayet Salnamesine Göre Kastamonu Vilayeti”, Zonguldak Karaelmas Üniversitesi Sosyal Bilimler Dergisi 6/1 (2010), 269.

5 - M. Zeydin Yıldız - Orhan Deniz, "Maarif Salnamelerine Göre 19. Yüzyllın Sonunda Van'da Eğitim ve Kültürel Hayat”, 199.

6 - Gülizar Tanrıdağ, Çorlu İlçesi Sosyo-Ekonomik Yapısı, (Tekirdağ: Namık Kemal Üniversitesi, Sosyal BilimlerEnstitüsü, Yüksek Lisans Tezi, 2016) 1. 
Sosyal ve ekonomik yapıyı ilgilendiren alt başlıklardan oluşan ve tablolarla desteklenen bu araştırmada, Çorlu kazasının demografik yapısı, mahalle ve karyeleri, eğitim-öğretim faaliyetleri, tarihi yapıları, geçim kaynakları gibi konular incelenmeye çalışmıştır. Yapılan çalışmada, başlarda Gayrimüslimlerin yoğun olarak yaşadığı bir yerleşim yeri olan Çorlu'nun zamanla bu kimliğinden sıyrıldığı özellikle XIX. yüzyılın sonlarında, Osmanlı Devleti'nin kaybettiği savaşlar nedeniyle elden çıkan topraklardan gelen yoğun Müslüman göçüyle birlikte şehirdeki Müslüman nüfusun bir hayli artarak Gayrimüslim nüfusu geride bıraktığ1 tespit edilmiştir. Çalışmada ayrıca, ekonomik faaliyetler bakımından da gelişmiş bir yerleşim yeri olan Çorlu'nun özellikle küçükbaş hayvan yetiştiriciliği alanda önemli bir yere sahip olduğu tespit edilmiştir.

\section{NÜFUS}

XIX. yüzyılın sonlarında Tekfurdağı Sancağı'na bağlı kaza statüsünde bulunan Çorlu'ya ait en erken nüfus kayıtları, Sultan II. Mahmut dönemine rastlar. H.1246//M.1830-31 yılında gerçekleşen nüfus sayımına göre Çorlu kazasında Müslümanların yanı sıra Gayrimüslimler de yoğun olarak bulunmakta ve nüfusun büyük çoğunluğunu Gayrimüslimler oluşturmaktadır. Nüfus sayısı bakımından Müslüman erkek nüfusun 1.008, tahmini toplam Müslüman nüfusunun 2.016 $6^{7}$ olduğu bu dönemde, Gayrimüslim erkek nüfusu 2.086, tahmini toplam Gayrimüslim nüfusu ise $4.172{ }^{\prime}$ dir. $^{8}$ H.1261//M.1845 yılına ait temettuat kayıtlarında ise nüfus sayısında büyük değişimin yaşanmadığının görüldügü kazada, toplam hane sayısı 1.286, toplam nüfus miktarı ise 6.445 olarak belirlenmiştir. ${ }^{9}$

1877-78 Osmanlı-Rus Savaşı'nın ardından elden çıkan topraklardan başlayan göçlerle birlikte Çorlu’nun nüfus yapısında önemli değişiklikler meydana gelmiştir. ${ }^{10}$ Öyle ki bu yıllardan sonra kazadaki nüfus sayıs1 ve yapısı önemli oranda değişerek Müslümanlar sayıca Gayrimüslimlerden üstün duruma gelmişlerdir. 1890'l1 yıllarda toplam nüfusun 7.950'ye ulaştığı kazada Müslümanlara ait toplam nüfus 3.613 iken Gayrimüslimlere ait toplam nüfus 4.268' dir. Gayrimüslimlere ait nüfusun 3.023'ünün Rumlara ait olduğu kazada, Ermenilere ait nüfus sayıs1 662, Yahudilere ait nüfus say1s1 288, Bulgarlara ait nüfus say1s1 ise 295'dir. Ayrıca bu dönemde kazada 60 kadar Kıpti de bulunmaktadır. ${ }^{11}$ Yüzyılın sonuna doğru ise nüfus sayısının bir hayli arttığı kazada toplam nüfus 25.023'e yükselmiştir. Müslümanlara ait nüfus sayısının ilk kez Gayrimüslim nüfusu geride bıraktığı bu dönemde, Müslümanlara ait toplam nüfus 13.954 iken Gayrimüslimlere ait nüfus sayısı ise 10.669'dur. Gayrimüslimlere ait nüfus sayısının büyük çoğunluğunun Rumlara ait olduğu kazada, Rumlara ait nüfus sayısı bu dönemde 7.579, Ermenilere ait nüfus sayıs1 1.482, Yahudilere ait nüfus sayıs1 797, Bulgarlara ait nüfus sayısı ise 811 'dir. Bu dönemde kazadaki Kıpti sayısı da 400 kadardır. ${ }^{12}$ Kazadaki toplam nüfus sayısının yıllara göre dağılımı da aşağıdaki tabloda gösterildiği gibidir:

Tablo 1. Çorlu Kazasının Yıllara Göre Nüfus Sayısı

\begin{tabular}{|c|c|c|c|}
\hline $\mathbf{1 8 3 0}$ & $\mathbf{1 8 4 5}$ & $\mathbf{1 8 9 0}$ & $\mathbf{1 9 0 0}$ \\
\hline 6.188 & 6.445 & 7.950 & 25.023 \\
\hline
\end{tabular}

XIX. yüzyılın sonlarında nüfus sayısının önemli miktarda arttığı kazada, nüfusun büyük bir kısmı mahallelerde ikamet etmektedir. 1830'lu yıllarda toplam 19 mahalle, 21 karye/çiftlikten oluşan Çorlu ${ }^{13}$ zamanla mahalle ve karye/çiftlik sayısında değişikliklere uğramıştır. Öyle ki 1845 yılına ait temettuat kayıtlarında,

7 - Nuran Koltuk, Osmanlı Döneminde Çorlu Nüfus Defterlerinde, ed. D. T. Alıkılıç, (İstanbul: Çorlu Belediyesi Yayınları, 2017), 57.

8 - N. Koltuk, Osmanlı Döneminde Çorlu Nüfus Defterlerinde, 107.

9 - Nuran Koltuk, Osmanlı Döneminde Çorlu Temettuat Defterlerinde, C. I-II, ed. A. A. Akhan, (İstanbul: Çorlu Belediyesi Yayınları, 2017) 46.

10 - N. Koltuk, Osmanlı Belgelerinde Çorlu, ed. S. A. Sağlamçubukçu, (İstanbul: Çorlu Beldiyesi Yayınları, 2017), 41.; Mehmet Serez, Tekirdağ Tarihi ve Coğrafyası Araştırmaları, (Ankara: Dönmez Ofset, 2007), 184.; Mehmet Serez, Tekirdă̆ Tarihi ve Coğrafyası Araştırmaları 2 Odalar ve Dernekler, (Ankara: Dönmez Ofset 2014), 50.

11 - (EVS, H. 1309, 363).

12 - (EVS, H. 1317, 511).

13 - N.Koltuk, Osmanlı Döneminde Çorlu Nüfus Defterlerinde, 57-107. 
nüfus kayıtlarından farklı olarak Cami-i Atik ve Ermeni Mahallesi'ne yer verilmeyerek kazadaki toplam mahalle sayısı 17, karye/çiftlik sayısı ise 21 olarak belirlenmiştir. ${ }^{14}$ XIX. yüzyılın sonlarında ise mahalle sayısının çok fazla değişmediğ $1^{15}$ kazada bulunan mahalleler ve bu mahallelerin Müslim ve Gayrimüslim tebaa arasındaki dağılımı şu şekildedir:

\section{Tablo 2. Çorlu’daki Mahallelerin Nüfus Dağılımı}

\begin{tabular}{|l|c|c|}
\hline Yerleşim Yeri & Müslüman & Gayrimäslim \\
\hline Cami-i Atik Mahallesi & Müslüman & \\
\hline Baba Halil Mahallesi & Müslüman & \\
\hline Cami-i Cedid Mahallesi & Müslüman & \\
\hline Muhyiddin Mahallesi & Müslüman & \\
\hline Arabacıbaşı Mahallesi & Müslüman & \\
\hline Hacı Resul Mahallesi & Müslüman & \\
\hline Öksüz Gazi Mahallesi & Müslüman & \\
\hline Güvenşah Mahallesi & Müslüman & \\
\hline Hatip Mahallesi & Müslüman & \\
\hline Hızır Ağa Mahallesi & Müslüman & Gayrimüslim \\
\hline Ohlas Mahallesi & Müslüman & Gayrimüslim \\
\hline Şeyh Sinan Mahallesi & Müslüman & Gayrimüslim \\
\hline Hacı Yakup Mahallesi & & Gayrimüslim \\
\hline Yahudi Mahallesi & & Gayrimüslim \\
\hline Papa Dimitri Mahallesi & & Gayrimüslim \\
\hline Piskopos Mahallesi & & 6 \\
\hline Papa Yani Mahallesi & & \\
\hline Durusu Mahallesi & & \\
\hline Ermeni Mahallesi & 13 & \\
\hline Toplam & & \\
\hline
\end{tabular}

Kaynak: Nuran Koltuk, Osmanlı Döneminde Çorlu Nüfus Defterlerinde, 57; Nuran Koltuk, Osmanlı Döneminde Çorlu Temettuat Defterlerinde, 107.

Tablo (2)'de görüldüğü üzere Çorlu kaza merkezindeki mahallelerin büyük çoğunluğu Müslümanlara ait yerleşim yeridir. 6 adet Gayrimüslim mahallesinin bulunduğu kaza merkezinde, Müslümanların ve Gayrimüslimlerin bir arada yaşadığı mahalleye rastlanılmamıştır. Oysa kırsal alandaki durum bundan biraz farklıdır. Zira kırsal alandaki yerleşim yerlerinin büyük çoğunluğunda Müslümanlar ve Gayrimüslimler bir arada yaşamaktadır.

Tablo (3)'de detaylıca görüleceği üzere kazadaki karye ve çiftliklerin büyük çoğunluğu Müslümanların ve Gayrimüslimlerin bir arada yaşadığı yerleşim yerleridir. Toplam 11 adet Müslüman ve Gayrimüslim tebaanın bir arada yaşadığı karye/çiftliğin bulunduğu kazada ikinci sırada Gayrimüslimlere ait karye/çiftlikler, üçüncü sırada ise Müslümanlara ait karye/çiftlikler yer almaktadır.

14 - N.Koltuk, Osmanlı Döneminde Çorlu Temettuat Defterlerinde, 45-46.

15 - 1891-1892 yıllarına ait kayıtlarda kazadaki mahalle sayısı 12 olarak yer almaktadır. Ancak bu mahallelerin isimleri ve kimlere ait olduğu net olarak belli değildir. Ayrıntılı bilgi için Bkz. (EVS, H. 1309, 359). 
Tablo 3. Çorlu'daki Karye ve Çiftliklerin Nüfus Dağılımı

\begin{tabular}{|c|c|c|c|}
\hline Yerleşim Yeri & Müslüman & Gayrimüslim & Müslim/Gayrimüslim \\
\hline Öksüzce Çiftliği & & & Müslim/Gayrimüslim \\
\hline Deregündüzlü Köyü & Müslüman & & \\
\hline Sarılar Çiftliği & Müslüman & & \\
\hline Armağanşah Çiftliği ve Köyü & & & Müslim/Gayrimüslim \\
\hline Süleymanlı Çitliği & & & Müslim/Gayrimüslim \\
\hline $\begin{array}{l}\text { Sevindikli Köyü } \\
\text { Çorum Kaya Köyü }\end{array}$ & $\begin{array}{l}\text { Müslüman } \\
\text { Müslüman }\end{array}$ & & \\
\hline Çengerli Mustafa Bey Çiftliği & & Gayrimüslim & \\
\hline Müsellem Köyü & & Gayrimüslim & \\
\hline Kara Mehmed Çiftliği & & Gayrimüslim & \\
\hline Köprüce ve Çengerli Çiftliği & & & Müslim/Gayrimüslim \\
\hline Karaköy Çiftliği & & & Müslim/Gayrimüslim \\
\hline Aşağı Çengerli Çiftliği & & & Müslim/Gayrimüslim \\
\hline Maksutlu Çiftliği & & & Müslim/Gayrimüslim \\
\hline Muratlı Çiftliği & & & Müslim/Gayrimüslim \\
\hline Türkmenli Çiftliği & & & Müslim/Gayrimüslim \\
\hline Ohlas Köyü & & Gayrimüslim & \\
\hline İsaca Çiftliği & & & Müslim/Gayrimüslim \\
\hline Germiyan Köyü & & Gayrimüslim & \\
\hline Paşalı Ağa Yeniköy & & Gayrimüslim & \\
\hline Hacı Şermet Köyü & & Gayrimüslim & \\
\hline Kara Sinekli Çiftliği Köyü & & & Müslim/Gayrimüslim \\
\hline Toplam & 4 & 6 & 11 \\
\hline
\end{tabular}

Kaynak: N. Koltuk, Osmanlı Döneminde Çorlu Nüfus Defterlerinde, 57; N. Koltuk, Osmanlı Döneminde Çorlu Temettuat Defterlerinde, 107.

XIX. yüzyılın sonlarına doğru mahalle sayısında önemli bir değişimin olmadığı Çorlu' da, kırsal alandaki yerleşim yerleri sayıca bir hayli artarak 39'a yükselmiştir. Bunlardan 37'sinin tespit edildiği bu yerleşim yerlerinin dağılımı aşağıda gösterildiği gibidir.

\section{Tablo 4. Salnâmelere Göre Çorlu'daki Karye ve Çiftlikler}

\begin{tabular}{|l|l|}
\hline Karye & \multicolumn{1}{l|}{ Çiftlik } \\
\hline İsaca, Kızıl Pınar, Yanık Ağıl, Öksüzce, & Yukarı Çengerli, Güberice, Paşalı Ağa, \\
Kara Mehmed, Sevindikli, Bayatl, Çorum, & Hacı Muradlı, Aşağı Çengerli, Yeni, \\
Süleymanlı, Germiyan, Türbedere, Velimeşe, & Kadıöo, Serikli, Türkmenli, \\
Hacı Şermet, Ohlas, Muradlı, Sarılar, & \\
Şehbaz, Yakublar, Armağanşah, Kırkağaç, & \\
Müsellem, Yalefli (Alefli), Kara Senet, Kırkgeyikli, & \\
Balanlı, Deregündüzlü, Maksudlu, Kadıköy & \\
\hline Toplam: 28 & 9 \\
\hline
\end{tabular}

Kaynak: (EVS, H. 1310, 679).

Tablo (4)'de görüldüğü üzere kırsal alandaki yerleşim yerlerinden bazıları daha erken döneme ait kayıtlarda yer almasına karşın bazıları ise daha eski kayıtlarda yer almayan yüzyılın sonuna doğru kazadaki nüfus ve yerleşim yapısının gelişmesiyle birlikte ortaya çıkan yerleşim yerleridir. Ancak daha eski dönemlere 
ait kayıtlarda yer almasına karşın 1900'lü yılların başında mevcut olmayan yerleşim yerleri de bulunmaktadır. Bu yerleşim yerlerinin durumu net olarak bilinmemekle birlikte kendisine yakın bir başka yerleşim yeri birleşmiş olabileceği veya isim değişikliğine uğramış olabileceği kuvvetle muhtemeldir.

Kırsal alanda bulunan bu yerleşim yerlerinden merkeze en uzak ve en yakın olanları ise, Sevindikli, Yanık A ğıl, Muradlı, Germiyan, Türbedere Hacı Şermet, Yalefli, Paşalı Ağa çiftliği ve Şehbaz karyesi şeklinde siralanmaktadır. ${ }^{16}$

\section{EĞiтiM}

Sosyal hayatın bir diğer önemli unsuru ise eğitimdir. Salnâmelerden elde edilen kayıtlara göre; Çorlu kaza merkezinde XIX. yüzyılın sonlarında ilköğretim düzeyinde eğitim veren ${ }^{17}$ Mekteb-i İbtidâîler ile devletin memur ihtiyacını karşılamak amacıyla kurulan ${ }^{18}$ ortaokul düzeyindeki Mekteb-i Rüştiyeler, Medreseler ve Gayrimüslimlere ait okullar bulunmaktadır. Bu mekteplerin 3 tanesinin Müslümanlara ait olduğu kaza merkezinde, Gayrimüslimlere ait mektep sayıs1 5'dir. ${ }^{19}$ Gayrimüslimlere ait bu okulların 2'si Rumlara, 1'i Ermenilere ve 1'i ise Musevilere aittir. Rum ve Ermeni okulları, İnas ve Zükur Mektebi olarak ayrışmaktadır. ${ }^{20}$ Musevilere ait mektep ile ilgili olarak ise kayıtlarda herhangi bir bilgiye rastlanılmamıştır. ${ }^{21}$

Bu okullarda eğitim gören Müslim ve Gayrimüslim öğrenci sayısı ise şu şekildedir:

Tablo 5. Müslümanlara Ait Mektepler ve Öğrenci Sayıları

\begin{tabular}{|l|l|}
\hline Müslümanlara Ait Mektepler & Örenci Sayısı \\
\hline İbtidâ-î Mektebi & 60 \\
\hline Rüşdiye Mektebi & 33 \\
\hline
\end{tabular}

Kaynak: (EVS, H. 1309, 361).

Tablo 6. Gayrimüslimlere Ait Mektepler ve Öğrenci Sayıları

\begin{tabular}{|l|l|}
\hline Gayrimüslimlere Ait Mektepler & Öğrenci Sayısı \\
\hline Rum İnas Mektebi (Kız) & 70 \\
Rum Zukür Mektebi (Erkek) & 100 \\
\hline Ermeni İnas Mektebi (Kız) & 60 \\
Ermeni Zükur Mektebi (Erkek) & 80 \\
\hline
\end{tabular}

Kaynak: (EVS, H. 1309, 361).

Toplam 403 öğrencinin eğitim gördüğü bu okullardaki eğitim kadrosu ise şu şekildedir:

Tablo 7. Müslim ve Gayrimüslim Mekteplerin Kadrosu

\begin{tabular}{|l|l|}
\hline Memuriyet & İsmi \\
\hline Mektebi Rüşdiye Muallimi & Tahir Efendi \\
\hline Mektebi Rüşdiye Muallimi & Ömer Efendi \\
\hline Mektebi Rüşdiye Muallimi & Edhem Efendi \\
\hline Mektebi Rüşdiye Muallimi & Ali Efendi \\
\hline
\end{tabular}

16 - (EVS, H. 1310, 679).

17 - Himmet Kanal,“Sultan II. Abdülhamid'in Osmanlı Eğitimine Yaptığı Önemli Bir Katkı: Emlâk-1 Hümâyûn’a İnşa Edilen Okullar", SUTAD, 40, (2016), 164.

18 - Biray Çakmak - Bulut Gökçeoğlu, “Milas Kazası Erkek Rüştiye Mektebi”, HÜTAD, 25, (2016) 42

19 - (EVS, H. 1317, 511).

20 - (EVS, H. 1309, 361).

21 - Bunların yanı sıra kırsal alandaki yerleşim yerlerin birçoğunda da inşa edilmiş Mekteb-i İbtidâîler bulunmaktadır. Ancak bunlara ait öğrenci sayısı net olarak bilinmemektedir. Himmet Kanal, 2016, "Sultan II. Abdülhamid'in Osmanlı Eğitimine Yaptı̆g 1 Önemli Bir Katkı: Emlâk-1 Hümâyûn’a İnşa Edilen Okullar”, 165. 


\begin{tabular}{|l|l|}
\hline Mektebi İbtidâ-î Muallimi & Ömer Efendi \\
\hline Zükur Mektebi İbtidâ-î Muallimi & Hasan Efendi \\
\hline Zükur Mektebi İbtidâ-î Muallimi & Halil Efendi \\
\hline İnas Mektebi İbtidâ-i Muallimi & Hüseyin Efendi \\
\hline Gayrimüslim Mektebi Muallimi & İbrahim Efendi \\
\hline Muallim-i Salis Rikâ & Tahir Bey \\
\hline Bevvâb & Osman Efendi \\
\hline
\end{tabular}

Kaynak: (EVS, H. 1310, 250-679; EVS, H. 1311, 221; EVS, H. 1313, 227; EVS, H. 1314, 212; EVS, H. 1315, 216-217; 27, 229; EVS, H. 1317, 229).

\section{TARIHÎYAPILAR}

\subsection{MÜSLÜMANLARA AIT DINÎ YAPILAR}

Türklerin bölgeyi fethinden sonra imar çalışmalarının hız kazandığı Çorlu'da hemen hemen her mahallede birer mescit inşa edilmiştir. Mescitlerin yanı sıra üç büyük caminin bulunduğu kazadaki bu camilerden Fatih Sultan Mehmet döneminde inşa olunan Fatih Cami, Çorlu'daki en eski camilerden birisidir. Bu caminin yanı sıra salnâmelerde yer alan kayıtlara göre; kazada Kanuni Sultan Süleyman döneminde inşa olunan Süleymaniye Cami ve harap vaziyette bulunan yalnızca minaresi mevcut olan Arabacıbaşı Cami bulunmaktadır. ${ }^{22}$

\section{FATIH CAMI}

Çarşı Cami ismi ile anılan ve Cami-i Atik Mahallesi sınırları içerisinde yer alan Fatih Cami, kazanın ortasından geçen cadde üzerine inşa edilmiştir. ${ }^{23}$ Zaman içerisinde defalarca kez tamir olunan ${ }^{24}$ caminin duvarları ve minaresi ilk yapıdan kalmadır. Duvarları moloz ile kaba yonma taşlarla yapılan caminin minaresinin gövdesi çok kalın, peteği incedir. Bina içerden 11,60x17,5 m. ve dişardan 13,85x20 arasındadır. Ayrıca 3.85 m. derinliğinde bir cemaat yeri vardır. Bu cemaat yeri 1825 tarihine kadar açık bir halde iken bu tarihten sonra caminin gördüğü tamir esnasında ahşap direkler arasına camekânlar konularak kapatılmıştır. Cami altta 14, üstte 15 pencere ile ziyadesiyle aydınlık bir görünüme sahiptir. ${ }^{25}$ Evvelce on iki odalı medresesi bulunan caminin medresesinin yerinde bugün müftülük binası bulunmaktadır. ${ }^{26}$

\section{SÜLEYMANIYE CAMI}

Daha eski dönemlerde Cami-i Kebir ismi ile anılan ve Muhiddin Mahallesi'nin sınırları içerisinde yer alan Süleymaniye Cami, Kanuni Sultan Süleyman döneminde, Mimar Sinan'ın ustası Acem İsa tarafından yaptırılmıştır. Bünyesinde bir medrese ve bir imaret bulunan bu caminin medresesi yirmi odalıdır. Medresesinde hocalık yapanlardan bazılarının şeyhülislâmlığa kadar yükseldiği bu caminin imaretinde günde iki defa sıcak yemek verilmiştir. ${ }^{27}$

Minaresi ve dış cemaat yeri 1898 depreminde yıkılan caminin dış cemaat yeri 1949 yılında Evkaf İdaresi tarafından tamir ettirilmiştir. Bu tamir esnasında caminin kubbelerinin kurşunları da değiştirilmiştir. 1951 yılında ise halk tarafından minaresi tamir ettirilen caminin önüne bir de şadırvan yaptırılmıştır. ${ }^{28}$

22 - (EVS, H. 1310, 678).

23 - M. Serez, Tekirdağ Tarihi ve Coğrafyası Araștırmaları, 265.

24 - N. Koltuk, Osmanlı Belgelerinde Çorlu, 130.

25 - M. Serez, Tekirdağ Tarihi ve Coğrafyası Araştırmaları, 266.

26 - Muhiddin Tuna, Geçmişten Bugüne Çorlu, (İstanbul: Siralar Matbaası, 1963), 83-84.

27 - M.Tuna, Geçmişten Bugüne Çorlu, 85.

28 - M.Tuna, Geçmişten Bugüne Çorlu, 85. 
Caminin kıble kapısı üzerinde bulunan kitabesinde ise şu dizeler yazılıdır:

"Şah Süleyman sahib-el-hayrat

Fikir gerdemki kuyemes tarih

Hatif-i gayb güft tarihin

Kıldı bu cami-i şerifi bina

Küned an vakti in sada peyda

Kad bena mabedan lihubbi Huda” Sene 928 M.1521/1522.

\section{ARABACIBAŞI CAMI}

Salnâmelerde harap bir halde tasvir edilen ve yalnızca minaresinin varlığından bahsedilen Arabacıbaşı Cami, modern kaynaklarda yer almamaktadır. Modern kaynaklarda bu cami ile ilgili olarak Arabacıbaşı Cami'nin yerine Çorlulu Hacı Bornalı tarafından inşa edilen Bornalı Cami’nden bahsedilmektedir. Üstü kiremitli olan bu caminin minaresi tek şerefelidir. ${ }^{29}$

Bunların yanı sıra modern kaynaklarda yer alan bilgilere göre şehirde ayrıca Tahtalı Cami, Yeşiltepe Cami, Reşadiye Cami, Bahçelievler Cami, Havra Cami adında pek çok cami ismi bulunmaktadır. Salnâmelerde yer almamasına karşın günümüzde Cemaliye Mahallesi sınırları içerisinde bulunan Havra Cami, Havra iken Camiye dönüştürülmüştür. ${ }^{30}$ Ayrıca Sultan II. Abdülhamid zamanında Türbedere, Velimeşe, Kızılpınar ve bazı köylerde Sultan Mustafa, Sultan III. Mehmed, Sultan Ahmed, Sultan II. Osman ve Yavuz Sultan Selim isimleri verilen camiler inşa ettirilmiştir. ${ }^{31}$

\subsection{GAYRIMÜSLIMLERE AIT DINÎYAPILAR}

Gayrimüslim nüfusun yoğun olarak ikâmet ettiği Çorlu'da salnâmedeki kayıtlara göre; 2 Rum ve 1 Ermeni Kilisesi ve 1 de Yahudi Havrası vardır. ${ }^{32}$ Rumlara ait kiliselerden biri eski, diğeri ise yenidir. Rumlara ait eski kilisenin bir, yeni kilisenin ise iki kapısının bulunduğu kazada, Ermenilere ait kilise iki kapılı ve bir miktar avluludur. ${ }^{33}$ Modern kaynaklarda ise Tekirdağ ve çevresindeki gayrimüslimlere ait dinî yapılarla ilgili olarak; Çorlu'da Ermenilere ve Rumlara ait 1 kilise ve 1 adet de günümüzde hâlâ cami olarak kullanılan havranın varlığından bahsedilmektedir. ${ }^{34}$ Ancak bunların mevcut konumları ile ilgili olarak bir bilgi bulunmamaktadır.

\section{3. ÇEŞMELER}

1892-93 yıllara ait kayıtlarda Çorlu'da harap ve mamur halde bulunan toplam 23 çeşmenin ${ }^{35}$ varlığından bahsedilmesine karşın yüzyılın sonuna doğru bu say1 8'e olarak belirtilmiştir. ${ }^{36}$ Çeşmelerden Çoban Dede ${ }^{37}$, Çardaklı Agob ${ }^{38}$ ve Ermeni Mahallesi'nde bulunan Yeni Çeşme ${ }^{39}$ kayıtlarda yer almasına karşın diğer çeşmelerin isimlerine rastlanılmamıştır. Ancak kayıtlarda her ne kadar ismine rastlanılmasa da Çorlu'daki en

29 - M. Serez, Tekirdağ Tarihi ve Coğrafyası Araştırmaları, 266.

30 - M. Serez, Tekirdağ Tarihi ve Coğrafyası Araştırmaları, 267.

31 - N. Koltuk, Osmanlı Döneminde Çorlu Nüfus Defterlerinde, 20.

32 - (EVS, H. 1310, 678).

33 - (EVS, H. 1309, 360).

34 - M. Serez, Tekirdağ Tarihi ve Coğrafyası Araștırmaları, 359

35 - (EVS, H. 1310, 678).

36 - (EVS, H. 1318, 1123).

37 - (EVS, H. 1309, 361).

38 - (EVS, H. 1309, 361).

39 - (EVS, H. 1309, 360). 
eski çeşme Fatih Sultan Mehmet tarafından inşa ettirilen Fatih Cami'nin hemen arka avlusuna bitişik olarak yapılan Fatih Çeşmesi'dir. 1453 yılında yapıldığı tahmin edilen çeşmenin inşa tarihi net olarak bilinmemesine karşın araştırmacıların pek çoğu cami ve çeşmenin benzer tarihlerde yapıldığı konusunda hem fikirlerdir. ${ }^{40}$

Modern kaynaklarda kazadaki çeşmeler; Hürriyet Çeşmesi, Acı Çeşme, Silâhtar Çeşmesi, Hastane Çeşmesi, Havra Çeşmesi, Çukur Çeşme, Yeni Çeşme, Eyüp Ağa Çeşmesi, Çoban Çeşme, Gazi Çeşmesi, Ac1 Hamam Çeşmesi, Kumyol Çeşmesi, Çardaklı Çeşme, Naylon Çeşme, Çarşı Çeşmesi ${ }^{41}$ Kumlu ve Tavanlı Çeşmesi şeklinde sıralanmaktadır. ${ }^{42}$

Çorlu'da bu yapıların yanı sıra 1 hükümet konağ $1,{ }^{43} 1$ hamam, ${ }^{44} 1$ belediye dairesi, ${ }^{45} 1$ telgrafhane, ${ }^{46} 8$ han ${ }^{47}$ ve 1 hapishane mevcuttur. ${ }^{48}$ Ermeni Kilisesi vakfina ait olan kayıtlarda da icar ile tutulduğu belirtilen Hükümet Konağ $1^{49}$ tuğla ile inşa edilmiş olup iki katlıdır. Osmanlı hükümeti zamanında üst katı inhisarlar idaresi, alt katı da esnaf dükkânları olarak kullanılan bu konak, Kurtuluş Savaşı'nda sonra Milli Emlâk'a devredilmiştir. ${ }^{50}$

\section{EKONOMIK FAALIYETLER}

Salnâmelerde yerleşim yerlerinin sosyal yapısının yanı sıra ekonomik yapısı hakkında da önemli bilgilere ulaşmak mümkündür. Söz konusu bu bilgiler sayesinde, şehirdeki arazi, tarım ve hayvan miktarı gibi pek çok konu hakkında ayrıntılı verilere ulaşılabilir. Bu bağlamda bu başlık altında; Çorlu'daki arazi dağılımı, tarım ve hayvancılık faaliyetleri ile birlikte sanayi alanındaki gelişmeler incelenmeye çalışılacaktır.

\subsection{ARAZI VE TOPRAK MIKTARI}

XIX. yüzyılın sonlarında Çorlu'da, 617.646 dönüm mezru yani ekili dikili arazi ve gayri mezru ekilip dikilmeyen arazi, 9.867 kıta tarla, 7.188 kıta bağ, 51 kıta çayır, 27 kıta mera, 11 kıta bahçe, 6 kıta orman ve çalılık arazi kayıt altına alınmıştır. ${ }^{51}$ Mezru ve gayri mezru arazinin bir bütün olarak verilmesi nedeniyle, toplam ekilebilir ve ekilmeyen arazi miktarının tespitinin mümkün olmamasına karşın 1845 yılına ait temettuat kayıtlarındaki veriler, mezru ve gayri mezru arazi hakkında fikir vermektedir. Zira temettuat verilerine göre, Çorlu kazasında bulunan arazilerin \%43,44’ünü ekilebilir alanlar, \%51,37'sini ise ekilip dikilmeyen alanlar oluşturmaktadır. ${ }^{52}$ Ancak gayri mezru alanları tamamen verimsiz ekilemeyen alanlar olarak düşünmemek gerekir. Nitekim gayri mezru alanların bir kısmını, toprağı dinlendirmek maksadıyla nadasa bırakılan alanlar oluşturmaktadır. Bunun yanı sıra gayrimezru alanların varlığı; toprak sisteminin bozulması, tarım dışı faaliyetlerin artması veya hane sahiplerinin mal varlıklarını ve ekonomik gelirlerini düşük göstermek gibi nedenlerle de açıklanabilmektedir. ${ }^{53}$ Ekilebilir arazilerin büyük çoğunluğunu tarla ve bağların oluşturduğu kazadaki arazilerin dağılımı ise şu şekildedir:

40 - M. Serez, Tekirdağ Çeşmeleri, Şadırvanları, Sebilleri, (Ankara: Dönmez Ofset, 2014), 70.

41 - M. Tuna, Geçmişten Bugüne Çorlu, 76-78.

42 - M. Serez, Tekirdă̆ Tarihi ve Coğrafyası Araştırmaları, 268.

43 - (EVS, H. 1309, 359).

44 - (EVS, H. 1310, 678).

45 - (EVS, H. 1309, 359).

46 - (EVS, H. 1317, 511).

47 - (EVS, H. 1317, 511).

48 - (EVS, H. 1310, 667).

49 - (EVS, H. 1310, 667).

50 - M. Tuna, Geçmişten Bugüne Çorlu, 86-87.

51 - (EVS, H. 1309, 362; EVS, H. 1310, 677; EVS, H. 1317, 512; EVS, H. 1318, 1124).

52 - N. Koltuk, Osmanlı Döneminde Çorlu Temettuat Defterlerinde, 87.

53 - N. Koltuk, Osmanlı Döneminde Çorlu Temettuat Defterlerinde, 87. 


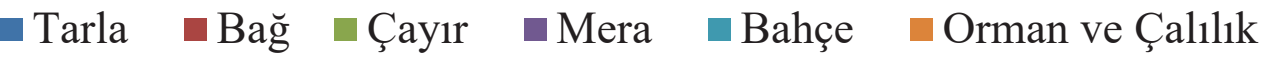

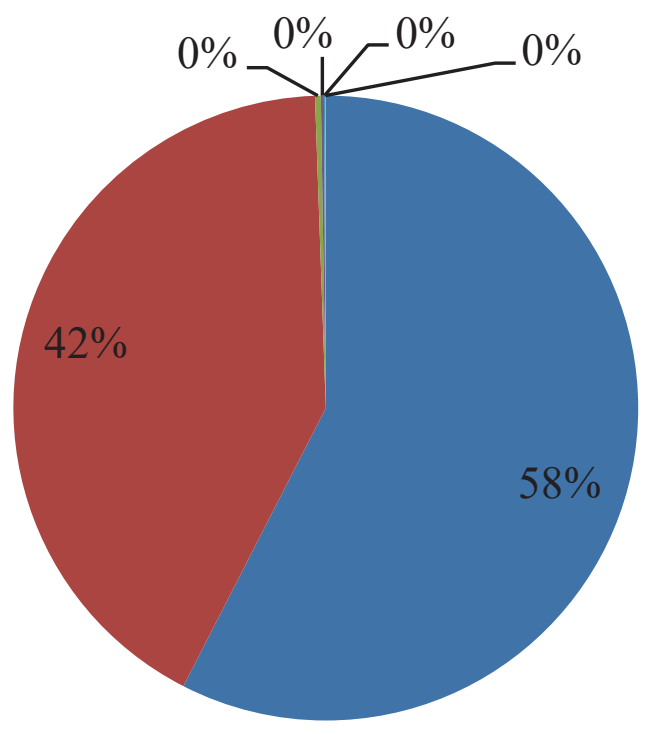

Şekil 1. Çorlu'da Arazi Dağılımı

\subsection{TARIM}

Osmanlı Devleti'nin önemli şehirlerinden Tekfurdağı Sancağı'nın bir parçası olduğunu belirttiğimiz Çorlu, İstanbul'un iaşesi için de bir hayli önemli bir yere sahiptir. Toprağa dayalı üretimin hayli yaygın olduğu kazada, halkın büyük bir kısmı geçimi tarımsal faaliyetlerden sağlamaktadır. İklim koşullarının yanı sıra verimli arazileri sayesinde de tarım alanında gelişmiş bir yerleşim yere sahip olan Tekfurdağı, tarihin her döneminde bu alandaki önemini korumuştur. Öyle ki, Macar Kralı II. Fransuva Rakoczi'nin Yaveri Mikes Kelemen'in Tekfurdağı'nda bulunduğu yıllarda kaleme aldığı mektuplarında, şehrin tarım alanında ne kadar gelişmiş bir yerleşim yeri olduğu görülmektedir. Zira Kelemen mektuplarında, bu bölge ile ilgili olarak; şehirde ne tarafa gidilirse gidilsin boş bir arazi bulmanın mümkün olmadığından, toprağın mükemmel işlendiğinden bahsetmektedir. ${ }^{54} \mathrm{Bu}$ coğrafyanın bir parçası olan Çorlu için de benzer şeyleri söylemek mümkündür. Nitekim yukarıdaki tabloda görüldüğü üzere halkın büyük kısmı geçimini tarla, bağ ve bahçe işleri ile uğraşarak sağlamaktadır.

Daha ziyade hububat yetiştiriciliğinin yaygın olduğu bu bölgede özellikle buğdayın ayrı bir yeri vardır. Ak, sarı ve karabaşak isimlerinde üç çeşit buğdayın yetiştirildiği bu bölgede yetiştirilen bu buğdayların verimliliği bir hayli yüksektir. ${ }^{55}$ Evliya Çelebi'ye göre; bu bölgede yetiştirilen buğday Şam Havran'inda yetiştirilen buğdaydan bile daha kalitelidir. ${ }^{56} \mathrm{Bu}$ bölgede yetiştirilen buğdayın bu kadar kaliteli olması saray mutfağında da ekseriyetle bu buğdayın tercih edilmesinin en önemli nedenidir. Kazada buğdayın yanı sıra arpa, çavdar, yulaf başta olmak üzere pek çok mahsul yetiştirilmektedir. Öyle ki 1889-1890 yıllarına ait kayıtlarda, Hayrabolu, Çorlu ve İnecik kazalarını içerisine alan bölgede bulunan zahire ve miktarı aşağıdaki gibi sıralanmıştır:

54 - Mikes Kelemen, Türkiye Mektupları, çev. S. Karatay, (Tekirdağ: Tekirdağ Valiliği Yayınları, 2006$), 52$.

55 - (EVS, H. 1310, 664); Aynı zamanda bu buğdayın tane kalitesi oldukça yüksek olup kuralığa dayanıklıydı. Özlem Sert, 1549 Rodosçuk'ta Bir Yıl, (Tekirdağ: Süleymanpaşa Belediyesi Yayınları, 2018), 85.

56 - Evliya Çelebi, Günümüz Türkçesiyle Evliyâ Çelebi Seyahatnâmesi, VIII/II, haz. A. Kahraman, İstanbul: Yapı Kredi Yayınlar1, 2011), 756. 
Tablo 8. 1889-1890 Yıllarında Çorlu, Hayrabolu ve İnecik’teki Zahire Miktarı

\begin{tabular}{|l|l|}
\hline Buğday & $\mathbf{3 7 8 5 0 0}$ \\
\hline Kızılca & 12800 \\
\hline Arpa & 12200 \\
\hline Çavdar & 10675 \\
\hline Kabluca ${ }^{57}$ & 30025 \\
\hline Darı & 5000 \\
\hline Kuş Yemi & 8675 \\
\hline Mısır & 45100 \\
\hline Burçak & 7500 \\
\hline Keten & 1500 \\
\hline Susam & 200 \\
\hline Nohut & 5000 \\
\hline Mercimek & 5000 \\
\hline Fasulye & 2000 \\
\hline Bakla & 2000 \\
\hline
\end{tabular}

Kaynak: (EVS, H. 1310, 668).

Sadece Çorlu kazasına ait senelik zahire miktarı ise aşağıdaki gibidir:

Tablo 9. Çorlu'nun Senelik Zahire Miktarı

\begin{tabular}{|l|l|}
\hline Zahire & Kile \\
\hline Buğday & 15000 \\
\hline Arpa & 8000 \\
\hline Yulaf & 25000 \\
\hline Keten & 500 \\
\hline Çavdar & 1500 \\
\hline
\end{tabular}

Kaynak: (EVS, H. 1317, 512).

Her ne kadar tablo (9)'da yer alan bilgiler kazada sadece buğday, arpa, yulaf, keten ve çavdar üretildiği izlenimini ortaya çıkarsa da bu doğru değildir. Çorlu'da kabluca, bakla, kuşyemi vb. ürünlerin yanı sıra özellikle Müsellem, Karaağaç, Yanık Ağıl, Öksüzce, İsaca ve Germiyan köylerinde tütün de yetiştirilmektedir. ${ }^{58}$ Ancak yetiştirilen bu ürünlerle ile ilgili olarak senelik kaç kile mahsul elde edildiğine dair bir bilgiye ulaşılmadığı için tabloya konulma gereği duyulmamıştır. Aksi takdirde modern kaynaklarda yer alan kayıtlar, şehirde pek çok farklı tahıl ürünü ile birlikte sebze ve meyve yetiştiriciliğinin yapıldığını doğrular niteliktedir. Öyle ki 1900'lü yılların ortalarında Çorlu'daki kışlık ve yazlık ekim sahalarını gösteren aşağıdaki tablo incelendiğinde, kazadaki yetiştirilen ürünler hakkında net bilgiye sahip olunacaktır.

Tablo 10. Çorlu'da Yetiştirilen Ürünler ve Arazi Miktarı

\begin{tabular}{|l|l|}
\hline Zahire & Hektar \\
\hline Buğday & 32000 \\
\hline Yulaf & 18000 \\
\hline Çavdar & 1600 \\
\hline Kabluca & 3000 \\
\hline Fĭ̆ & 1400 \\
\hline Kuş Yemi & 1500 \\
\hline
\end{tabular}

57 - Buğday arasında biten yulafa benzer hububat. Bkz. Şmseddin Sami, Kâmûs-ı Türkî, (İstanbul: Çağrı Yayınları, 2009), 1013.

58 - (EVS, H. 1309, 362). 


\begin{tabular}{|l|l|}
\hline Arpa & 1000 \\
\hline Keten & 700 \\
\hline Bakla & 200 \\
\hline Kolza & 70 \\
\hline Karpuz & 2000 \\
\hline Kavun & 1000 \\
\hline Ayçiçeği & 8000 \\
\hline Şeker Pancarı & 800 \\
\hline Çeltik & 200 \\
\hline
\end{tabular}

Kaynak: (Muhiddin Tuna, Geçmişten Bugüne Çorlu, 66-67).

Tablo (10)'da görüldüğü üzere Çorlu'da envai çeşit ürün yetiştirilmektedir. Özellikle hububat alanında gelişmiş bir yerleşim yeri olması nedeniyle daha ziyade buğday ve arpanın ön plana çıktı̆̆ kazada, yıllık 100.000 kile hububat ihraç olunmaktadır. Kazadaki yıllık ithalat miktarı ise 150.000 kile kadardır. ${ }^{59}$

\subsection{HAYVANCILIK}

Çorlu zirai faaliyetlerin yanı sıra hayvancılık sektöründe de gelişmiş yerleşim yerlerinden birisidir. Özellikle İstanbul'un iaşesi kapsamında sarayın ihtiyacı olan hububatın yanı sıra etin bir kısmı da Çorlu'dan gönderilirdi. ${ }^{60}$ Küçükbaş hayvan yetiştiriciliğinin büyükbaş hayvan yetiştiriciliğine nazaran daha fazla olduğu kazada temettuat kayıtlarına göre; 17.791 adet küçükbaş, 8.873 adet büyükbaş, 53 adet arı kovanı olmak üzere toplam 26.717 hayvan kaydı mevcuttur. Bu kayıtlara göre; en fazla hayvan kaydı Gayrimüslimlere ait Durusu, Papa Dimitri ve Papa Piskopos Mahallelerinde bulunmaktadır. Hayvan popülasyonunun \%75'ini oluşturan 10 köyün 6'sı Gayrimüslim tebaaya ait yerleşim yeri iken, 3 tanesi Müslümanlara, 1 tanesi de Müslümanlar ve Gayrimüslimlere ait ortak yaşam alanıdır. ${ }^{61} \mathrm{Bu}$ durum Gayrimüslimlerin hayvan yetiştiriciliği alanında Müslümanlara kıyasla daha fazla söz hakkına sahip olduğu da göstermektedir. Kazada en az hayvan yetiştiriciliğinin yapıldı ğı yerleşim yerleri ise temettuat kayıtlarında; Yahudi Mahallesi, Süleymanlı Çiftliği, Türkmenli Çiftliği ve Arabacı Mahallesi olarak sıralanmaktadır. Ayrıca kayıtlarda, Çorlu'daki tüm yerleşim yerlerinde büyükbaş hayvan yetiştiriciliğinin yapıldığı belirtilirken, Sevindikli Köyü, Muratlı Çiftliği, Sarılar Çiftliği, Hacı Yakup Mahallesi, Hatip Mahallesi, Muhyiddin Mahallesi, Deregündüzlü Köyü, Türkmenli Çiftliği, Öksüz Gazi Mahallesi, Güvenşah Mahallesi, Kara Mehmed Çiftliği, Paşalı Ağa Yeniköy, Ohlas Mahallesi, Arabacıbaşı Mahallesi, Süleymanlı Çiftliği ve Yahudi Mahallesi’nde küçükbaş hayvan yetiştiriciliğinin yapılmadığı yer almaktadır. ${ }^{62}$

Salnâmelerde yer alan kayıtlarda ise Çorlu kazasının dâhil olduğu Tekfurdağı Sancağı'nda 1889-1890 yılları arasında toplam 255.508 büyükbaş ve küçükbaş hayvan kaydının bulunduğu görülmektedir. Büyük çoğunluğu küçükbaş hayvanlarına ait olan bu kayıtların 167.999'u koyun, 45.058'i ise keçiye aittir. Geriye kalan hayvanlar arasında ise; öküz, manda, kara sığır ineği, manda buzağı, sığır buzağı vb. gibi büyükbaş hayvanlar bulunmaktadır. ${ }^{63}$ Çorlu'ya ait ağnam kayıtlarında kazada bulunan hayvan cinsi ve adedi şu şekilde sıralanmıştır:

59 - (EVS, H. 1309, 362).

60 - N. Koltuk, Osmanlı Belgelerinde Çorlu, 50.

61 - N. Koltuk, Osmanlı Belgelerinde Çorlu, 90.

62 - N: Koltuk, Osmanlı Belgelerinde Çorlu, 90.

63 - (EVS, H. 1310, 668). 
Tablo 11. Çorlu'daki Hayvanların İstatistikî Bilgileri

\begin{tabular}{|l|l|}
\hline Hayvan Cinsi & Adet \\
\hline Koyun ve Keçi & 54400 \\
\hline Kara Sı̆̆ır & 3000 \\
\hline Hergele & 2000 \\
\hline Manda & 500 \\
\hline
\end{tabular}

Kaynak: (EVS, H.1317,1124).

Her ne kadar salnâmelerdeki veriler, temettuat verileri gibi ayrıntılı olarak tutulmasa da tablo (11)'deki veriler, kazada özellikle küçükbaş hayvan yetiştiriciliğinin önemli bir yer tuttuğu göstermektedir. Öyle ki toplam hayvan sayısının 59.900 olduğu kazada, bunun \%90'ından fazlasını küçükbaş hayvanlar oluşturmaktadır. Büyükbaş hayvanların oranı ise sadece \% 9'dur. Hayvanların genel dağılım oranları ise aşağıdaki gibidir:

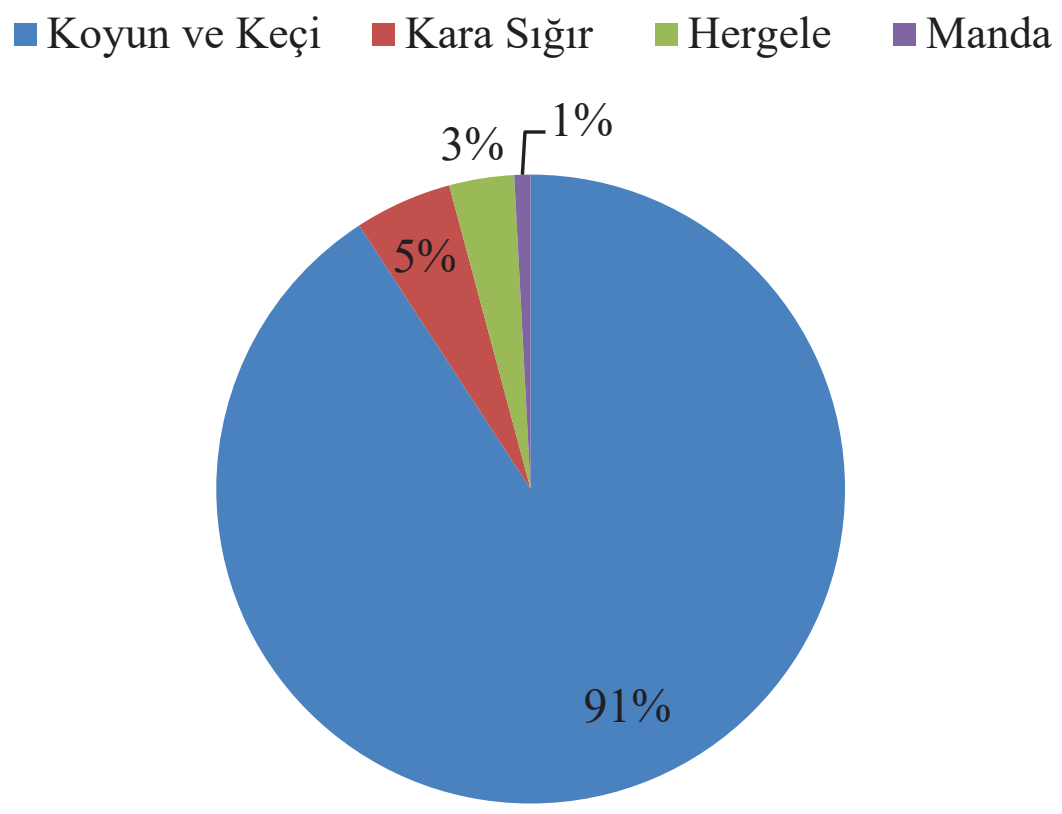

Şekil 2. Çorlu'daki Hayvanların Dağılımı Oranı

Şekil (2)'de görüldüğü üzere Çorlu'da kayıt altında alınan hayvanların \%90'nını koyun ve keçiler oluşturmaktadır. Büyükbaş hayvan yetiştiriciliği alanında ise çok fazla gelişmemiş olan kazada büyükbaş hayvanlarının oranı sadece $\% 9$ olup ilk sırada \%5'lik dilimle kara sığır yetiştiriciliği yer almaktadır. İkinci sırada \%3'lük dilimle hergele olarak atfedilen daha ziyade yük taşımaya henüz alıştırılmamış at ve eşek gibi binek hayvanlar yer aldığı kazada üçüncü sırada ise \%1'lik dilimle manda yetiştiriciliği yer almaktadır. Yetiştirilen bu hayvanlar, halkın günlük ihtiyacının yanı sıra devletin iaşe politikası için de bir hayli önemlidir. Özellikle sarayın ve ordunun et ihtiyacı söz konusu olduğunda devlet, kapsamlı bir iaşe politikası yürüterek, İstanbul'a yakın çevre iller başta olmak üzere Anadolu'nun pek çok şehrinden İstanbul'a iaşe akışı sağlard $1{ }^{64} \mathrm{Bu}$ şehirlerden biri olan Tekfurdağ $\mathrm{Sancağ} 1$ ve çevresi de İstanbul'un hububat ihtiyacinın yanı sıra hayvansal ürünler özellikle de et ihtiyacı olduğunda önemli merkezlerden biriydi. ${ }^{65}$ XIX. yüzyılın ilk

64 - Ahmet Uzun, İstanbul'un İaşesinde Devletin Rolü: Ondalık Ağnam Uygulaması 1753-1857, (Ankara: TTK Yayınları, 2006), 36.

65 - Kaya Göktepe, “Osmanlı Döneminde Tekirdağ’da Yapılan Hayvancıllğın İstanbul'un İaşesi ile Sanayi ve Ticari Faaliyetlerdeki Rolü”, Trakya Üniversitesi Sosyal Bilimler Dergisi, 20/1 (2018), 366. 
yarısına kadar başta İstanbul olmak üzere saray ve ordunun zaruri gıda ve et ihtiyacında önemli şehirlerden biri olan Tekfurdağı ve çevresi, daha sonra iaşe sistemi içerisinde XIX. yüzyılın ikinci yarısında önemini kaybetse de küçükbaş hayvan yetiştiriciliği konusunda önemini korumaya devam etmiştir. ${ }^{66}$ Özellikle koyun sürülerinden elde edilen sütlerden yapılan Çorlu peyniri oldukça lezzetlidir. Evliya Çelebi'nin aktarımına göre; Padişahlara ve bütün diyarlara hediye olarak gönderilen bu peynir, lezzet olarak Misır'ın Hâlûm peyniri ismi ile bilinen Hellim peynirini bile geride birakmaktadır. ${ }^{67}$

Küçükbaş hayvan yetiştiriciliğinin kazada bu kadar yaygın olmasının bir diğer nedeni ise; iklim ve coğrafi koşulların yanı sıra ekonomik olarak küçükbaş hayvan yetiştirmenin bütçeleri daha az zorlamasıdır. Zira şer'iye kayıtları incelendiğinde bir koyunun ortalama üç yüz üç yüz elli akçeye alıcı bulduğu görülürken, büyükbaş hayvan fiyatının bunun beş katına tekabül ettiği görülmektedir. ${ }^{6}$ Ayrıca toplumda temel tüketim maddesi olarak tüketilen etin ekseriyetle kuzu ve koyun eti olmasının ${ }^{69}$ ve koyunun iç yağlarından elde edilen yağların Osmanlı mutfağında kullanılmasının da küçükbaş hayvan yetiştiriciliğinin bu denli yaygın olmasında büyük etkisi vardır. ${ }^{70}$

Tarım ve hayvancılığın yanı sıra kazadaki bir diğer geçim kaynağı ise sanayidir. Her ne kadar ayrı bir alt başlık olarak inceleme yapılması için yeterli veriye sahip olunamasa da bu dönemde Çorlu'da küçük çaplı sanayi kuruluşlarının mevcut olduğu görülmektedir. Bir adet un, dört adet kiremit fabrikası bulunan kazadaki un fabrikasının değeri elli bin kuruş civarındadır. Senede 150.000 kile mahsul imal edilen bu fabrika, Tekfurdağı Sancağı içerisinde bulunan un fabrikaları içerisinde yıllık üretim miktarı açısından üçüncü sırada yer almaktadır. Un fabrikasının yanı sıra kazada dört adet kiremit fabrikası ve tuğla ocağı bulunmaktadır. Üç tanesi Çorlu merkezde bir tanesi de Germiyan karyesinde yer alan kiremit fabrikası ve tuğla ocağından senelik 398.000 kiremit ve tuğla imal edilmektedir. ${ }^{71}$ Kazada bu fabrikaların yanı sıra 8 han, 377 dükkân ve mağaza, 12 değirmen, 30 firın, 60 kahvehane yer almaktadır. ${ }^{72}$

66 - K. Göktepe, Osmanlı Döneminde Tekirdağ’ da Yapılan Hayvancılı̆̆ı İstanbul'un İaşesi ile Sanayi ve Ticari Faaliyetlerdeki Rolü”, 370.

67 - N. Koltuk, Osmanlı Döneminde Çorlu Nüfus Defterlerinde, 18.

68 - (BOA. RŞS, nr. 1701, 128/1).; Necmettin Aygün, “Osmanlı Devleti Kırsalında İktisadî Örüntüler ve Trabzon’da Koyun (Sürü) Sahipleri (1722)”, Karadeniz İnceleme Dergisi, 13/25, (2018), 26.

69 - Kelemen, Türkiye Mektupları, 60-61.

70 - Mehmet Türkhan, 18. Yüzyılın İkinci Yarısında İstanbul'un Et İaşesinin Temini: Hassa Kasabbaşılık Kurumu, (İstanbul: Marmara Üniversitesi, Sosyal Bilimler Enstitüsü, Yüksek Lisans Tezi, 2006) 23.

71 - (EVS, H. 1309, 362).

72 - (EVS, H. 1317, 512). 


\section{SONUÇ}

XIX. yüzyılın sonunda Çorlu'nun sosyal ve ekonomik hayatının ele alındığı bu çalışmada, birçok önemli tespite ulaşılmıştır. Şöyle ki, XIX. yüzyılın sonlarında Tekfurdağı Sancağı'na bağlı kaza statüsünde bulunan Çorlu, Türkler, Ermeniler, Yahudiler, Rumlar ve Bulgarların bir arada yaşadığı kozmopolit bir yerleşim yeridir. Mahallerin büyük kısmının Müslümanlara ait olduğu yerleşim yerinde, Gayrimüslimlere ait mahalle sayısı 6, Müslümanlara ait mahalle sayısı ise 13’tür. Müslim ve Gayrimüslim tebaanın bir arada yaşadığı mahallenin bulunmadığı kazada, kırsal alandaki yerleşim yerleri için aynı şey söz konusu değildir. Zira kırsal alandaki yerleşim yerlerinin büyük çoğunluğu Müslim ve Gayrimüslim tebaanın bir arada yaşadığı alanlardır. Ortak yerleşim alanlarının yanı sıra Gayrimüslimlere ait karye/çiftlik sayısının daha fazla olduğu kazada, Müslümanlara ait karye/çiftlik sayısı ise dörttür. Bu alanlardaki toplam nüfus sayısının yüzyılın sonun doğru 25.023 olduğu kazada Müslümanlara ait toplam nüfus sayıs1 13.954, Gayrimüslimlere ait nüfus sayısı ise 10.669 'dur. Gayrimüslimlere ait nüfus sayısının büyük çoğunluğunun Rumlara ait olduğu kazada, Rumlara ait nüfus sayıs1 7.579, Ermenilere ait nüfus sayıs1 1.482, Yahudilere ait nüfus sayıs1 797 ve Bulgarlara ait nüfus sayısı ise 811 'dir. Bu dönemde kazada ayrıca 400 kadar Kıpti yaşamaktadır.

XIX. yüzyılın sonlarında Çorlu merkezi başta olmak üzere kırsal alanlarında eğitim ve kültür ilgili kurumlarında gelişmiş olduğu görülmektedir. Çeşitli derecede Müslüman ve Gayrimüslimlere ait kız ve erkek okullarının bulunduğu kazada, gayrimüslimlere ait öğrenci sayısı Müslümanlara ait öğrenci sayısından fazladir.

Ekonomik faaliyetler, işgücü olanakları bakımından gelişmiş bir yerleşim yeri olan Çorlu'da tarım ve hayvancılık önemli bir geçim kaynağıdır. Toprağın dağılımının büyük kısmının tarla ve bağ alanlarının oluşturduğu kazada Akdeniz ve karasal iklimin etkisine bağlı olarak üzüm, kavun, karpuz gibi meyve çeşitleri ile birlikte buğday, arpa, yulaf, keten tohumu, çavdar gibi çeşitli tahıl ürünleri yetiştirilmektedir. Özellikle de hububat alanında gelişmiş bir şehir olan Tekfurdağı Sancağı'nın bir parçası olan Çorlu'da yetiştirilen tahıl ürünleri ekseriyetle saray mutfağında tercih edilmişstir.

Bir diğer önemli geçim kaynağının hayvan yetiştiriciliği olduğu kazada, halk daha ziyade küçükbaş hayvan yetiştiriciliğini tercih etmiştir. Özellikle koyun ve keçi yetiştiriciliğinin bir hayli yaygın olduğu şehirde büyükbaş hayvan yetiştiriciliği ise çok yaygın değildir. Sanayi alanında ise çok fazla gelişmemiş kazada küçük çaplı da olsa bazı sanayi kuruluşları mevcuttur. 


\section{KAYNAKÇA}

\section{ARŞiV BELGELERi}

\section{RODOSCUK ŞER'IYE SICILI}

BOA. RŞS, nr. 1701, 128/1.

\section{EDIRNE VILAYET SALNÂMESI}

H. 1308 (1891) Tarihli Edirne Vilayet Salnamesi.

H. 1309 (1892) Tarihli Edirne Vilayet Salnamesi.

H. 1310 (1892) Tarihli Edirne Vilayet Salnamesi.

H. 1310 (1893) Tarihli Edirne Vilayet Salnamesi.

H. 1311 (1895) Tarihli Edirne Vilayet Salnamesi.

H. 1312 (1896) Tarihli Edirne Vilayet Salnamesi.

H. 1313 (1897) Tarihli Edirne Vilayet Salnamesi.

H. 1314 (1898) Tarihli Edirne Vilayet Salnamesi.

H. 1315 (1899) Tarihli Edirne Vilayet Salnamesi.

H. 1316 (1900) Tarihli Edirne Vilayet Salnamesi.

H. 1317 (1901) Tarihli Edirne Vilayet Salnamesi.

H. 1318 (1902) Tarihli Edirne Vilayet Salnamesi.

\section{ARAŞTIRMA ESERLERI}

Aydın, Bilgin, "Salname”, C. 36, DIA, İstanbul: Türkiye Diyanet Vakfı Yayınları, 2009, 51-54.

Aygün, Necmettin, “Osmanlı Devleti Kırsalında İktisadî Örüntüler ve Trabzon’da Koyun (Sürü) Sahipleri (1722)”, Karadeniz İnceleme Dergisi, 13/25 2018, 11-68.

Çakmak, Biray - Gökçeoğlu, Buket, Milas Kazası Erkek Rüştiye Mektebi, HÜTAD, 25 2016, 41-64.

Çelebi, Evliyâ. Günümüz Türkçesiyle Evliyâ Çelebi Seyahatnâmesi, VIII/II, Haz. Kahraman, A., İstanbul: Yapı Kredi Yayınları, 2011.

Göktepe, Kaya, “Osmanlı Döneminde Tekirdağ'da Yapılan Hayvancılığın İstanbul’un İaşesi ile Sanayi ve Ticari Faaliyetlerdeki Rolü”, Trakya Üniversitesi Sosyal Bilimler Dergisi, 20/1 2018, 361-382.

Kanal, Himmet, Sultan II. Abdülhamid'in Osmanlı Eğitimine Yaptığı Önemli Bir Katkı: Emlâk-1 Hümâyûn'a İnşa Edilen Okullar, SUTAD, 40 2016, 151-176.

Karakök, Tunay, “H. 1288 (M. 1871) Tarihli Kastamonu Vilayet Salnamesine Göre Kastamonu Vilayeti”, Zonguldak Karaelmas üniversitesi Sosyal Bilimler Dergisi, 6/11 2010, 267-276.

Kelemen, Mikes, Türkiye Mektuplarl, Çev. Karatay, S., Tekirdağ: Tekirdă̆ Valiliği Yayınları, 2006.

Koltuk, Nuran, Osmanlı Belgelerinde Çorlu, Ed. Sağlamçubukçu, S, A., İstanbul: Çorlu Beldiyesi Yayınları, 2017.

Koltuk, Nuran, Osmanlı Döneminde Çorlu Temettuat Defterlerinde, C. I-II, Ed. Akhan, A. A., İstanbul: Çorlu Belediyesi Yayınları, 2017.

Koltuk, Nuran, Osmanlı Döneminde Çorlu Nüfus Defterlerinde, Ed. Alıkılıç, D. T, İstanbul: Çorlu Belediyesi Yayınları, 2017.

Pakalın, M. Zeki, Osmanlı Tarih Deyimleri ve Terimler Sözlüğ̈̈, C. III, Ankara: MEB Yayınları, 1993.

Sami, Şemseddin, Kâmûs-ı Türkî, İstanbul: Çağrı Yayınları, 2009.

Serez, Mehmet, Tekirdağ Tarihi ve Coğrafyası Araştırmaları, Ankara: Dönmez Ofset, 2007.

Serez, Mehmet, Tekirdağ Çeşmeleri, Şadırvanları, Sebilleri, Ankara: Dönmez Ofset, 2014.

Serez, Mehmet, Tekirdağ Tarihi ve Coğrafyası Araştırmaları 2 Odalar ve Dernekler, Ankara: Dönmez Ofset, 2014.

Sert, Özlem, 1549 Rodosçuk'ta Bir Yıl, Tekirdağ: Süleymanpaşa Belediyesi Yayınları, 2018.

Tanrıdağ, Gülizar, Çorlu İlçesi Sosyo-Ekonomik Yapısı, Tekirdağ: Namık Kemal Üniversitesi Sosyal Bilimler Enstitüsü, Yüksek Lisans Tezi, 


\section{6.}

Tuna, Muhiddin, Geçmişten Bugüne Çorlu, İstanbul: Sıralar Matbaası, 1963.

Türkhan, Mehmet, 18. Yüzyılın İkinci Yarısında İstanbul'un Et İaşesinin Temini: Hassa Kasabbaşılık Kurumu, İstanbul: Marmara Üniversitesi Sosyal Bilimler Enstitüsü, Yüksek Lisans Tezi, 2006.

Uzun, Ahmet, İstanbul'un İaşesinde Devletin Rolü: Ondalık Ağnam Uygulaması 1753-1857, Ankara: TTK Yayınları, 2006.

Yıldız, M. Zeydin - Deniz, Orhan, "Maarif Salnamelerine Göre 19. Yüzyılın Sonunda Van’da Eğitim ve Kültürel Hayat”, Doğu Coğrafya Dergisi, 35 2016, 197-208. 


\section{EXTENDED ABSTRACT}

\section{AIM AND SCOPE}

Çorlu, which is the largest and most developed district of Tekirdağ Province today, was a district of Tekfurdağ 1 Sanjak at the end of the XIX. century. Tekfurdağ 1 Sanjak, which has an important place in the food policy of the Ottoman since the early periods due to its current strategic location, is one of the settlements on which researchers highly emphasize. In these studies, where Tekfurdağ 1 Sanjak was examined as a whole, it was determined that the district of Çorlu was not studied much. However, the district of Çorlu, which has sufficient documents and records in the Ottoman Archive, should be handled and examined independently from the Tekfurdağı Sanjak.

Until today, some studies have been carried out directly on Çorlu. However, these studies focus on the mid of XIX. century. There is no study used Salnames as main source and related with end of the XIX. century. Therefore, in this study; provincial salnames have used as the main source, it has been tried to focus on the social and economic structure of the city. In this study, which deals with the current situation of Çorlu at the end of the XIX. century, a number of questions such as the population of the city, settlements, educational activities, workforce opportunities were found to answer how the social and economic life in the city was maintained. At the same time, this study aims to show how salnames can be used in city history studies.

\section{METHODS}

In this study, scanning model has been adopted. First of all, Edirne Provincial Salnames included in the ISAM database were accessed and then the bibliography of the studies obtained by searching both the online catalogues of the libraries and Google search engines were examined. Especially in this study, in which YÖK thesis centre database was used for theses, ULAKBİM database was used for articles.

\section{FINDINGS}

In this study, it was determined that the population of Çorlu increased significantly between 1890-1900 and reached 25.023. This number was only 7.950 in the 1890s. Loosing lands of Ottoman Empire due Because Muslim population coming from these lands caused significant changes in both the population number and the population structure of the city. Until those years, the majority of the population in the city continued to be non-Muslims. 
In Çorlu, which is a developed settlement in terms of economic activities and labour force, $\% 99$ of the lands belong to fields and vineyards. The remaining areas are places such as pasture, bush and forest. In the field of animal husbandry, the rate of ovine animals raised in the county which is a developed settlement, is $\% 91$, while this number is only $\% 5$ in the proportion of bovine animals.

\section{CONCLUSION}

Çorlu, which is a settlement where Turks, Greeks, Armenians, Jews, Greeks and Bulgarians live together, was a settlement with a large non-Muslim population in the beginning, but over time it became a settlement, where Muslims became superior in number. In this, after Ottoman Empire's conquest of the region, besides the Turkmen population, who were settled in order to accelerate the Turkification of the region since the second half of the XIX. century, The Muslim population coming from the lands lost due to wars, had a great influence. Çorlu, which was a settlement consisting of 21 villages / farms and 19 neighbourhoods in the first half of the XIX. century, did not change the number of neighbourhoods towards the end of the century, but it is seen that the number of settlements in rural areas increased considerably to 39. Although the neighbourhoods are divided into Muslim and non-Muslim neighbourhoods, it is not possible to say the same for all rural settlements. Because in the vast majority of rural settlements, Muslims and non-Muslims live together. This situation, in a sense, shows that there is no sharp border between the rural residents and the citizens tend to live together.

Agriculture and animal husbandry have an important place the in county which is a developed settlement in terms of economic activities and labour opportunities. Çorlu has an important place in the grain and meat needs of Istanbul, especially since it is very close to Tekfurdağ 1 , which is one of the food centres of Istanbul in terms of grain and meat needs. Although Tekfurdağ 1 port lost its importance towards the end of the XIX. century, Çorlu continued to maintain its importance, especially in the field of sheep and goat breeding. In the county, where not much development has been observed in the industrial area, there are a few flour and tile factories as well as some small businesses. 